Revista Universo Contábil, ISSN 1809-3337

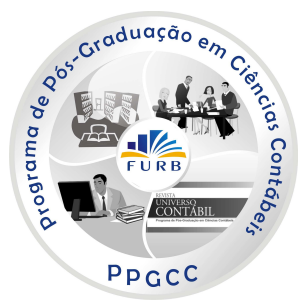

\title{
O PORTO E A INSTRUÇÃO CONTABILÍSTICA: APRECIAÇÃO CRÍTICA DA DISCIPLINA DE CONTABILIDADE E DO CURSO DE COMÉRCIO DA ACADEMIA POLITÉCNICA DO PORTO, 18371
}

\author{
PORTO AND THE ACCOUNTING EDUCATION: A CRITICAL REVIEW OF THE \\ ACCOUNTING DISCIPLINE AND THE COMMERCE COURSE OF POLYTECHNIC \\ ACADEMY OF PORTO, 1837
}

\section{CONTABILIDAD Y EDUCACIÓN EN OPORTO: EVALUACIÓN CRÍTICA DE LA DISCIPLINA DE CONTABILIDAD Y DEL CURSO DE COMERCIO ENSEÑADO EN LA ACADEMIA POLITÉCNICA DE OPORTO, 1837}

\author{
Miguel Gonçalves \\ Mestre em Contabilidade e Auditoria pela Universidade de Aveiro \\ Professor do Instituto Superior de Contabilidade e Administração de Coimbra \\ do Instituto Politécnico de Coimbra \\ Endereço: Quinta Agrícola, Bencanta \\ CEP: 3040-316 - Coimbra - Portugal \\ E-mail: mgoncalves@iscac.pt \\ Telefone: +351239802000 \\ Maria da Conceição da Costa Marques \\ Doutora em Gestão, Especialidade de Contabilidade pela Universidade Aberta \\ Professora do Instituto Superior de Contabilidade e Administração de Coimbra \\ do Instituto Politécnico de Coimbra \\ Endereço: Quinta Agrícola, Bencanta \\ CEP: $3040-316$ - Coimbra - Portugal \\ E-mail: conceicao.m@netcabo.pt \\ Telefone: +351239802000
}

\section{RESUMO}

Em matérias relacionadas com História da Contabilidade, a questão do ensino da Contabilidade nas antigas escolas de Comércio aparece por vezes negligenciada. Portugal é uma excepção a esta regra, por via dos artigos internacionais publicados sobre a Aula de Comércio (1759), instituição escolar fundada em Lisboa. Com inspiração nesses estudos, o artigo adopta no entanto outro ângulo de visão, redireccionado a atenção para outro pólo comercial que não a capital de Portugal - a cidade do Porto no segundo terço do século XIX.

\footnotetext{
1 Artigo recebido em 27.10.2011. Revisado por pares em 11.01.2012. Reformulado em 26.03.2012. Recomendado para publicação em 28.03.2012 por Ilse Maria Beuren (Editora). Publicado em 30.07.2012. Organização responsável pelo periódico: FURB.
} 
Desta forma, o paper estuda a problemática do ensino contabilístico numa escola portuguesa de ensino superior fundada em 1837 - a Academia Politécnica do Porto. Um dos dez cursos desta instituição escolar era o de Comércio, no qual os alunos aprendiam Contabilidade por partidas dobradas. Assim, o objectivo central deste estudo é o de dar a conhecer os principais aspectos relacionados com o ensino da Contabilidade na Academia Politécnica do Porto, nomeadamente aqueles que se prendem com o programa de estudos da 11 . $^{\mathrm{a}}$ cadeira (Comércio e Economia Industrial) e com os factores que contribuíram para a reduzida procura do Curso de Comércio. O principal contributo do trabalho diz respeito à análise crítica da disciplina de Contabilidade leccionada na Academia Politécnica do Porto.

Palavras-chave: História da Contabilidade. Portugal. Século XIX. Aulas de Comércio. Academia Politécnica do Porto.

\section{ABSTRACT}

In disciplines regarding Accounting History, issues concerning Accounting education in the old schools of commerce many times seem to be neglected. Portugal is an exception to this rule, by means of international articles published on the Portuguese School of Commerce, an establishment founded in Lisbon in 1759. Inspired by these studies, the article adopts, however, a different angle, directing attention to another commercial pole other than the capital of Portugal - the city of Porto in the second third of the $19^{\text {th }}$ century. This paper studies the issues of accounting education of a Portuguese school founded in 1837, the Polytechnic Academy of Porto. One of the ten courses of this institution was the School of Commerce, in which students learned Accounting by double-entry. Thus, the focal objective of this study is to raise awareness of the main aspects related to the teaching of accounting in the Polytechnic Academy of Porto, in particular those which are related to the $11^{\text {th }}$ discipline (Commerce and Industrial Economy), and with the factors that contributed to the reduced demand for the Course of Commerce. The main contribution of this work is regarding a critic review of the accounting discipline taught at the Polytechnic Academy of Porto.

Keywords: Accounting History. Portugal. $19^{\text {th }}$ century. Schools of Commerce. Polytechnic Academy of Porto.

\section{RESUMEN}

En los asuntos relacionados con el tema de la Historia de la Contabilidad, la enseñanza de Contabilidad en las antiguas escuelas de comercio surge a veces olvidada. Portugal es una excepción a esta regla, por medio de artículos internacionales publicados sobre la Escuela de Comercio, fundada en Lisboa en 1759. Inspirados en estos estudios, el artículo adopta sin embargo otro ángulo de visión, dirigiendo la atención a otro centro comercial - la ciudad de Oporto en el segundo tercio del siglo XIX. Así, el artículo estudia el problema de la enseñanza de la contabilidad en una escuela portuguesa de educación superior fundada en 1837, la Academia Politécnica de Oporto. Uno de los diez cursos de esta escuela fue la Escuela de Comercio, en el que los estudiantes aprendieron contabilidad por partida doble. Por lo tanto, el objetivo central de este estudio es dar a conocer los principales aspectos relacionados con la enseñanza de la Contabilidad en la Academia Politécnica de Oporto, en particular las que se refieren al plan de estudios de $11 .^{a}$ disciplina (Comercio y Economía Industrial) y con los factores que contribuyeron a la reducción de la demanda para el Curso de Comercio. La principal aportación del trabajo se refiere a la revisión de la disciplina contable enseñada en la Academia Politécnica de Oporto.

Palabras clave: Historia de la Contabilidad. Portugal. Siglo XIX. Escuelas de Comércio. Academia Politécnica de Oporto. 


\section{INTRODUÇÃO}

Em Portugal, as matérias ligadas ao ensino da Contabilidade no século XIX constituem um aspecto negligenciado pela literatura (GONÇALVES, 2011b). Ora porque a tónica vem colocada na Aula de Comércio de Lisboa (1759-1844), fundada em 1759 pelo Marquês de Pombal, principal Secretário de Estado de D. José (1750-1777) (RODRIGUES et al., 2004b), ora porque o século XIX representou para Portugal uma época muito instável, sobretudo a partir da Revolução Liberal de 1820, a verdade é que escasseiam estudos sobre o binómio 'Contabilidade e Educação' reportados ao Portugal de Oitocentos. Neste âmbito, o trabalho representa um subsídio para a temática do conhecimento contabilístico num ambiente que não a clássica e intensivamente estudada Aula de Comércio de Lisboa, pretendendo configurar uma resposta, em parte, à chamada efectuada por Pereira $(2009$, p. 4) para que se atenuem "as lacunas na produção de estudos sobre a problemática do ensino comercial e do ensino da Contabilidade no período Oitocentista".

Em concreto, o artigo objectiva aumentar o conhecimento associado à História da Contabilidade Portuguesa, colocando em evidência o Curso de Comércio ministrado na Academia Politécnica do Porto, a partir do ano lectivo 1837-1838. Colocando o foco na análise crítica da disciplina de Contabilidade e no Curso de Comércio ministrado nesse estabelecimento de ensino. O paper reveste o modesto mérito de introduzir na literatura internacional o tópico geral da Academia Politécnica do Porto e, particularmente, o do ensino da Contabilidade aí ministrado, circunstâncias insuficientemente exploradas pela literatura.

$\mathrm{O}$ assunto de pesquisa que aqui abordamos revela-se importante por duas razões. Primeiro, porque existem poucos estudos em Portugal sobre o ensino da Contabilidade em contexto de Liberalismo, como escrevemos e, depois, porque o trabalho pretende ser uma réplica aos reptos de (1) Carmona e Zan (2002) e Carmona (2004) para que se torne mais amplo o mapa da variedade dos trabalhos em história da Contabilidade, designadamente pela expansão do segmento de tempo (antes de 1850) e da área geográfica (para além de países anglo-saxónicos) e de (2) Anderson-Gough (2009, p. 313) no sentido da elaboração "de mais investigações históricas de educação em Contabilidade em diversas épocas e lugares".

Espera-se que o artigo possa representar uma contribuição em ordem a encorajar futuros trabalhos na área de estudo 'Escolas de Comércio' dos séculos XVIII e XIX pela comunidade Portuguesa e Brasileira de historiadores da Contabilidade. É importante que investigadores de Portugal e do Brasil, preferencialmente trabalhando em conjunto (vejam-se, por exemplo, os trabalhos de Rodrigues et al., 2009, 2010, 2011) possam fornecer respostas válidas nesse domínio.

O protocolo utilizado na pesquisa respeitou os seguintes trâmites, de acordo com Raupp e Beuren (2006): i) quanto aos objectivos, descritiva; ii) quanto aos procedimentos, bibliográfica; e iii) quanto à abordagem do problema, qualitativa. Para Raupp e Beuren (2006), a pesquisa descritiva configura-se como um estudo intermediário entre a pesquisa exploratória e a explicativa, isto é, não se apresenta tão preliminar como a primeira nem tão aprofundada como a última. Para os mesmos autores, Raupp e Beuren (2006), as pesquisas bibliográficas são desenvolvidas mediante material já trabalhado, ou seja, fontes de evidência secundárias, principalmente livros e artigos científicos (e técnicos e/ou académicos). A investigação qualitativa é aquela que não utiliza instrumentos matemáticos, estatísticos ou econométricos (RAUPP; BEUREN, 2006; VIEIRA et al., 2009).

As principais fontes consultadas foram arquivos históricos, legislação, revistas científicas, manuais e revistas profissionais. Foram consultadas essas e não outras fontes, porque "a história da Contabilidade continua predominantemente baseada em documentos" (CARNEGIE; NAPIER, 1996, p. 28), sendo por isso "verdade que o recurso aos arquivos para a obtenção de dados primários continua a ser essencial na investigação em história da Contabilidade" (GOMES; RODRIGUES, 2009, p. 229). As fontes primárias foram extraídas 
do Arquivo da Biblioteca Nacional de Portugal, situada em Lisboa.

Tendo em vista a concretização do objectivo acima exposto, estruturámos a ordem de trabalhos em oito secções, incluindo esta introdução. Assim, a segunda secção oferece uma panorâmica dos trabalhos fundamentais da literatura nacional e internacional na temática em apreço - as Aulas de Comércio. A terceira secção presta atenção ao contexto político e educacional da época (1837) e, em especial, ao patrono da escola de que aqui nos ocupamos Passos Manuel. De seguida, faremos uma incursão pela oferta formativa da Academia Politécnica do Porto para, em continuação, tecermos considerações críticas sobre o programa de estudos da 11. ${ }^{\text {a }}$ cadeira da Academia (Comércio e Economia Industrial), por ser aquela que directamente mais se relaciona com a nossa especialidade - a Contabilidade. A sexta secção aludirá aos fundamentos da pouca procura do Curso de Comércio e a sétima terá como propósito efectuar uma viagem sobre os principais acontecimentos que o marcaram na Politécnica. Por fim, apresentamos as considerações finais e conclusões, bem como sugestões para futuras pesquisas.

Como advertência preliminar à leitura da exposição, salientamos que as transcrições respeitam a ortografia oficial e a sintaxe de então, no sentido de conservarmos o sabor próprio da época.

\section{REVISÃO DA LITERATURA}

O ensino da Contabilidade é hoje considerado uma sub-disciplina da Contabilidade e muitos académicos identificam o tópico como um dos seus interesses de investigação (ANDERSON-GOUGH, 2009).

Em Portugal, a investigação tocante à problemática da institucionalização do ensino da Contabilidade tem ganho particular relevância nos últimos anos, devido principalmente à exploração da temática relacionada com a Aula de Comércio de Lisboa (1759-1844), de que constituem exemplos os trabalhos de Ferreira et al. (1995), Rodrigues e Craig (2004, 2005, 2009), Rodrigues e Gomes (2002) e Rodrigues et al. (2003, 2004a, 2004b, 2007, 2010a, 2010b). Estes estudos afirmaram-se como contributos absolutamente cruciais para o entendimento dos factores políticos, económicos e sociais envolvidos na intervenção do Estado português na instrução contabilística e comercial, em 1759. Estas abordagens, abordando uma perspectiva da Contabilidade que leva em conta não apenas os aspectos técnicos da disciplina, mas sobretudo os políticos, sociais e económicos, trazem à discussão novos actores que tendem a aumentar a concepção da Contabilidade (HOPWOOD, 1985; NAPIER, 2006).

A importância do tema 'Aula de Comércio de Lisboa' justifica-se plenamente, na medida em que esta instituição escolar "é, cronologicamente, a primeira providência tomada pelo ministro de D. José para ocorrer às necessidades do nosso ensino" (CARVALHO, 2008, p. 458). Também Martins (1937, 1960), Felismino (1960), Gonçalves (1960), Azevedo (1961), Portela (1968), Costa (1980, 2009), Cardoso (1984), Santana (1985), Lopes (1992), Caiado (2000), Estevens (2009), Machado (2009), Silva (2009), Gonçalves (2010a, 2010b, 2010c) e Lira (2011), autores de estudos de cariz mais tradicional em História da Contabilidade (STEWART, 1992; GOMES; RODRIGUES, 2009) ou convencional (FLEISCHMAN et al., 1996; GOMES; RODRIGUES, 2009), apontam o ano de 1759 e a Aula de Comércio de Lisboa, fundada por Sebastião José de Carvalho e Melo (Marquês de Pombal, em 1770) como referências incontornáveis da fundação do ensino público, oficial e gratuito da Contabilidade em Portugal.

Ainda em Portugal, o assunto das antigas Escolas de Comércio, ou como eram vulgarmente designadas à época, as Aulas de Comércio (FERREIRA, 2010), tem despertado o interesse da comunidade contábil, nomeadamente naquilo que se prende com a segunda Aula de Comércio portuguesa, em termos cronológicos, estabelecida no país; a Aula de Comércio 
da Cidade do Porto (1803-1837), instituição integrante da Academia de Marinha e Comércio da Cidade do Porto. Exemplos de narrativas de história da Contabilidade adstritas a este tema podem encontrar-se em Azevedo (1982), Pereira (2001, 2006, 2009), Gonçalves (2011a) e Gonçalves e Marques (2011a, 2011b).

Voltando a Lisboa, a escola sucessora da Aula de Comércio, a Escola de Comércio (1844-1869), também tem sido alvo de interesse por parte dos investigadores portugueses, não obstante a atenção em muito menor escala que a literatura lhe tem dedicado (CARQUEJA, 2002; GONÇALVES, 2011b; GONÇALVES, 2012).

Trabalhos elaborados para dar a conhecer as primeiras escolas de Contabilidade no Brasil, Itália, Estados Unidos, França e Espanha foram conduzidos respectivamente por (os tópicos 2 a 5, colhidos em Gonçalves 2011a, p. 127):

1) Martins et al. (2006) e Peleias et al. (2007), os primeiros discutindo a primeira escola de Contabilidade do Estado de São Paulo, implementada em 1894, a Escola Politécnica de São Paulo e, os últimos, abordando a génese do ensino da Contabilidade no Brasil Colonial com as Aulas de Comércio estabelecidas com a vinda da família real portuguesa, em 1808;

2) Antoni (1987), apresentando uma evolução das scuole d'ábaco, em Pisa, no século XIV;

3) Previts e Merino (1979), aludindo a métodos de aprendizagem do século XVIII e ao nascimento das writing schools;

4) Maffre (1983, 1986), sobre as escolas superiores de comércio francesas no século XIX;

5) Fernández Aguado (1997a, 1997b, 1997c), realizando uma análise dos antecedentes mercantis em Espanha, para se centrar no caso da Escola de Comércio de Madrid (1828); García-Fuentes (1984), sobre a escola de Comércio da Corunha, no século XIX; e, ainda em Espanha, Arquero Montaño e Donoso Anes $(2000,2005)$, a propósito da génese do ensino oficial de Contabilidade, em 1799, na Escola de Comércio de Cádiz (inaugurada apenas em 1819).

Com o objectivo de enquadrar o presente estudo nos trabalhos de investigação realizados sobre a temática do Ensino da Contabilidade no contexto nacional e internacional (séculos XVIII-XIX), atente-se no Quadro 1.

\begin{tabular}{|l|l|l|l|}
\hline $\begin{array}{l}\text { Instituição de Ensino da } \\
\text { Contabilidade }\end{array}$ & \multicolumn{1}{|c|}{ País (Cidade) } & Ano ou Período & $\begin{array}{l}\text { Principais Estudos de } \\
\text { Referência }\end{array}$ \\
\hline Aula de Comércio de Lisboa & Portugal (Lisboa) & $1759-1844$ & $\begin{array}{l}\text { Rodrigues e Craig (2004, 2005, } \\
\text { 2009); Rodrigues e Gomes } \\
\text { (2002); Rodrigues et al. (2003, } \\
\text { 2004a, 2004b, 2007) }\end{array}$ \\
\hline Aula de Comércio do Porto & Portugal (Porto) & $1803-1837$ & Gonçalves (2011a) \\
\hline Escola de Comércio de Lisboa & Portugal (Lisboa) & $1844-1869$ & $\begin{array}{l}\text { Carqueja (2002); Gonçalves } \\
\text { (2011b) }\end{array}$ \\
\hline Scuole d'ábaco (Escolas de Ábaco) & Itália (Pisa) & Século XIV & Antoni (1987) \\
\hline Writing Schools & EUA & Século XVIII & Previts e Merino (1979) \\
\hline Escolas Superiores de Comércio & França & Século XIX & Maffre (1983) \\
\hline Escola de Comércio de Cádiz & Espanha (Cádiz) & 1799 & $\begin{array}{l}\text { Arquero Montaño e Donoso } \\
\text { Anes (2005) }\end{array}$ \\
\hline Escola de Comércio de Madrid & Espanha (Madrid) & 1828 & Fernández Aguado (1997a) \\
\hline Escola de Comércio da Corunha & Espanha (Corunha) & Século XIX & García-Fuentes (1984) \\
\hline Aulas de Comércio & Brasil Colonial & Depois de 1808 & Peleias et al. (2007) \\
\hline Escola Politécnica de São Paulo & Brasil (São Paulo) & 1894 & Martins et al. (2006) \\
\hline
\end{tabular}

Quadro 1 - Principais estudos de referência da problemática 'Aulas de Comércio/Escolas de Comércio' (revisão da literatura; séculos XVIII-XIX)

Fonte: Elaboração própria. 


\section{CONTEXTO POLÍTICO E EDUCATIVO (1837)}

Após a Revolução Setembrista de 1836, que proclama o regresso à Constituição de 1822 e o abandono da Carta Constitucional de 1826, Manuel da Silva Passos, o célebre Passos Manuel (1801-1862), ocupa no governo da rainha D. Maria II (1834-1853) a pasta de Secretário de Estado dos Negócios do Reino. O cargo de Secretário de Estado equivaleria hoje, ao de Ministro. O Presidente do Ministério (correspondente à função de chefe de Governo, agora) era Bernardo de Sá Nogueira de Figueiredo - mais conhecido por Sá da Bandeira (1795-1876). Evocando outro ângulo de visão, Manuel da Silva Passos tinha um irmão - José da Silva Passos - também destacado político, à época. Como eram partidários da mesma ideologia, "quando alguém se lhes referia, em separado, dizia o 'Passos, Manuel' ou o 'Passos, José'; daí a conhecida designação de 'Passos Manuel'” (CARVALHO, 2001, p. 560).

$\mathrm{O}$ nome de Passos Manuel aparece-nos hoje indissociavelmente ligado às três reformas implementadas no curto espaço de oito meses de que faz parte do Governo presidido por Sá da Bandeira - reforma do ensino primário, reforma da instrução secundária e reforma do ensino superior.

Mas se é incontestável de que é à criação da instrução secundária que o nome deste ministro irá ficar mais fortemente vinculado (a criação dos Liceus, por decreto referendado por Passos Manuel, em Dezembro de 1836, introduziu em Portugal o ensino secundário nas capitais do distrito), também no ensino superior a ânsia reformadora liberal de Passos Manuel se fez sentir de forma marcante, ao retirar corajosamente da Universidade de Coimbra o exclusivo deste modelo de ensino em Portugal. No pensamento de Carvalho (2001, p. 567), "a Universidade de Coimbra, única no país, sentia-se sempre molestada e ofendida quando se lhe retirava qualquer dos seus privilégios, e um deles era exactamente o monopólio do ensino superior".

Para a concretização desta medida, foram criadas duas escolas superiores, uma na capital e outra no Porto, datadas de 11 e 13 de Janeiro de 1837, respectivamente. Recebeu, a primeira, o nome de Escola Politécnica de Lisboa e, a segunda, o de Academia Politécnica do Porto, assumindo esta última a incumbência de formar comerciantes na segunda cidade do país. Em Lisboa, a Aula de Comércio da capital permanecia autónoma, não integrando a recém criada Escola Politécnica.

Para o caso que aqui tratamos, o Decreto de 13 de Janeiro de 1837 extingue a Academia Real da Marinha e Comércio da Cidade do Porto e funda, em seu lugar, com uma oferta de cursos alargada, a Academia Politécnica do Porto (GONÇALVES, 2011a). Em 1837, o ilustre reformador da instrução pública, Passos Manuel, escrevia o seguinte no decreto de ampliação e reformulação da Academia Real da Marinha e Comércio da Cidade do Porto em Academia Politécnica do Porto:

\footnotetext{
Attendendo à necessidade de plantar no pais as sciencias industriais, que differem muito dos estudos classicos e puramente scientificos, e até dos estudos theoricos contendo simplesmente a discripção das artes: e offerecendo para este fim a populosa e rica cidade do Porto a localidade mais apropriada pelo seu extenso commercio e outras muitas circunstancias; podendo a Academia Real da Marinha e Commercio satisfazer até certo ponto a este importante objecto, logo que receba uma organização mais conveniente: Hei por bem, em continuação do Plano Geral d'Estudos, decretar a parte relativa á reforma d'aquella Academia, que lhe foi apresentada pelo Vice-Reitor, encarregado d'este plano, e que vai assignado por Manoel da Silva Passos, Secretario d'Estado dos Negocios do Reino (BASTO, 1937, p. 151).
}

Reconvertida, a extinta Academia Real da Marinha e Comércio endossava a responsabilidade de instrução comercial e contabilística a uma escola superior politécnica 
que, como virá a relatar-se, percorreu sempre um caminho sinuoso ao longo dos quase três quartos de século da sua existência.

\section{BOSQUEJO DE UMA SUCINTA HISTÓRIA DO CURSO DE COMÉRCIO}

Com o objectivo de criar no Porto uma escola politécnica industrial, Passos Manuel, numa tentativa de descentralização do ensino superior e em linha com uma política de defesa de ensino técnico e científico, faz professar na Cidade Invicta um curso de Comércio, de nível superior que, a par de outros nove, contribuísse para suprir as necessidades de desenvolvimento da instrução nacional, no geral, e nortenha, em particular.

Como a Academia Politécnica do Porto tivera por antecessora a Academia de Comércio, era natural que não fossem esquecidos no plano da primeira os comerciantes (FREITAS, 1881a).

Seguindo o diploma magno de 13 de Janeiro de 1837, mais concretamente o seu art. ${ }^{\circ}$ 155..$^{\circ}$, reteiramos que a Politécnica do Porto, conservando o antigo núcleo de formação contabilística, comercial, matemática e naval, proveniente da Academia Real da Marinha e do Comércio da Cidade do Porto, vê assaz alargada a oferta formativa, conforme sintetizamos no Quadro 2.

\begin{tabular}{|l|c|}
\hline \multicolumn{2}{|c|}{ Cursos da Academia Politécnica do Porto (1837) } \\
\hline CURSO Art. 155 do Decreto de 13 de Janeiro de 1837 (Lei Geral da Instrução Pública) - \\
\hline Comércio & DURAÇÃO \\
\hline Directores de Fábricas & 3 anos \\
\hline Engenharia de Minas & 5 anos \\
\hline Engenharia de Pontes e Estradas & 5 anos \\
\hline Engenharia de Construção de Navios & 5 anos \\
\hline Engenharia Geográfica & 5 anos \\
\hline Oficial de Marinha & 5 anos \\
\hline Pilotagem & 5 anos \\
\hline Agricultura & 3 anos \\
\hline Artistas (Mestres em Desenho) & 3 anos \\
\hline
\end{tabular}

Quadro 2 - Oferta educativa da Academia Politécnica do Porto no ano de 1837

Fonte: Portugal (1837).

De acordo com Santos (1996, p. 99), "além dos cursos principais, ministrava também a Politécnica cursos preparatórios para os oficiais do exército: $1 .^{\circ}$ Engenheiros (4 anos); $2 .^{\circ}$ Artilheiros (3 anos); e 3. Infantaria e Cavalaria (2 anos)".

No sentido de servir o curso de Comércio, estabelecera o decreto orgânico de 13 de Janeiro de 1837 apenas uma cadeira, a 11. ${ }^{\text {a }}$, com a designação de Comércio e Economia Industrial. Ponderem-se os dados do Quadro 3 para melhor se esquematizar o plano geral das cadeiras ministradas na Academia destinadas a prover os dez cursos principais e os três secundários criados.

Inaugurada em 15 de Março de 1837, a Politécnica, instituição análoga à Escola Central de Artes e Manufacturas de Paris (LOPES, 1915; BASTO, 1937), dispunha, na sua prodigalidade de cursos e cadeiras, de uma secção separada no Instituto (secção de Comércio), que iria ter a seu cargo a tarefa de formar comerciantes portuenses hábeis nos processos de escrituração mercantil. Acrescente-se que a $1 .^{\mathrm{a}}, 2 .^{\mathrm{a}}, 3 .^{\mathrm{a}}, 5 .^{\mathrm{a}}$ e $6 .^{\mathrm{a}}$ cadeiras formavam a secção Matemática, a 7. ${ }^{a}, 8 .^{a}, 9 .^{a}$ e 10. ${ }^{a}$ a secção Filosófica, a 4. ${ }^{a}$, a secção de Desenho e, como se antevê, à 11. ${ }^{\mathrm{a}}$ cadeira correspondia a Secção Comercial ou Secção de Comércio. 


\begin{tabular}{|c|c|}
\hline \multicolumn{2}{|r|}{ Cadeiras da Academia Politécnica do Porto } \\
\hline \multicolumn{2}{|c|}{ - Art. 157 do Decreto de 13 de Janeiro de 1837 (Lei Geral da Instrução Pública) - } \\
\hline $\begin{array}{l}\text { CADEIRA } \\
\text { (n. }{ }^{\circ} \text { de ordem) }\end{array}$ & DESIGNAÇÃO COMPLETA \\
\hline 1. ${ }^{\mathrm{a}}$ cadeira & $\begin{array}{l}\text { Aritmética, Geometria Elementar, Trigonometria Plana, Álgebra até às equações } \\
\text { do } 2 .^{\circ} \text { grau }\end{array}$ \\
\hline 2. ${ }^{\mathrm{a}}$ cadeira & $\begin{array}{l}\text { Continuação de Álgebra, sua aplicação à Geometria, Cálculo Diferencial e } \\
\text { Integral, Princípios de Mecânica }\end{array}$ \\
\hline 3. ${ }^{\mathrm{a}}$ cadeira & Geometria Descritiva e suas aplicações \\
\hline 4. ${ }^{\mathrm{a}}$ cadeira & Desenho de Figura e Paisagem \\
\hline 5. ${ }^{\text {a }}$ cadeira & $\begin{array}{l}\text { Trigonometria Esférica, Princípios de Astronomia, Princípios Geodésicos, } \\
\text { Navegação Teórica e Prática }\end{array}$ \\
\hline $6 .^{\mathrm{a}}$ cadeira & Artilharia e Táctica Naval \\
\hline 7. ${ }^{\mathrm{a}}$ cadeira & História Natural dos três reinos da natureza aplicada às Artes e Ofícios \\
\hline $8 .^{\text {a }}$ cadeira & Física e Mecânica Industriais \\
\hline 9. ${ }^{\mathrm{a}}$ cadeira & Química, Artes Químicas e Lavra de Minas \\
\hline $10 .^{\mathrm{a}}$ cadeira & Botânica, Agricultura e Economia Rural e Veterinária \\
\hline 11. ${ }^{\mathrm{a}}$ cadeira & Comércio e Economia Industrial \\
\hline
\end{tabular}

Quadro 3 - Cadeiras criadas pelo Decreto de 13 de Janeiro de 1837 na Academia Politécnica do Porto Fonte: Portugal (1837).

Naturalmente que foram levantadas fundadas dúvidas quanto à sustentabilidade de vários cursos, nomeadamente por haver tão poucas cadeiras para tantos estudos. Campos (1859), Ribeiro (1876), Lopes (1915), Basto (1937) e Azevedo (1982) relatam-nos essas reservas, mas, no que sobrevém ao curso de Comércio, não obstante haver sido o mesmo organizado em apenas três cadeiras, como veremos, não tivemos oportunidade de encontrar argumentos válidos que nos fornecessem uma indicação mais precisa sobre se os receios também se estendiam a este curso.

No que tange à referida estrutura do curso para comerciantes (ou curso de Comércio), foi o mesmo disposto em três anos nas seguintes cadeiras, conforme Quadro 4.

\begin{tabular}{|c|c|c|}
\hline \multicolumn{3}{|c|}{ Plano dos 3 anos do Curso de Comércio na Academia Politécnica do Porto (1837) } \\
\hline ANOS & CADEIRAS & OBSERVAÇÕES \\
\hline \multirow[t]{2}{*}{ Ano 1} & 1. ${ }^{\mathrm{a}}$ cadeira & $\begin{array}{l}\text { Aritmética, Geometria Elementar, Trigonometria Plana, Álgebra até às } \\
\text { equações do } 2 .^{\circ} \text { grau }\end{array}$ \\
\hline & 1. ${ }^{\circ}$ ano da $11 .^{\mathrm{a}}$ cadeira & 1. ${ }^{\circ}$ ano de Comércio e Economia Industrial \\
\hline \multirow[t]{2}{*}{ Ano 2} & 2. ${ }^{\circ}$ ano da $11 .^{a}$ cadeira & 2. ${ }^{\circ}$ ano de Comércio e Economia Industrial \\
\hline & 4. ${ }^{\mathrm{a}}$ cadeira & Desenho de Figura e Paisagem \\
\hline
\end{tabular}

Quadro 4 - Cadeiras do Curso de Comércio da Politécnica do Porto (1837)

Fonte: Elaboração Própria.

\section{ANÁLISE CRÍTICO-PEDAGÓGICA DA DISCIPLINA DE ESCRITURAÇÃO (CONTABILIDADE) E DO CURSO DE COMÉRCIO}

A Politécnica funcionou pela primeira vez no ano lectivo de 1837 a 1838 , sem no entanto se fazer acompanhar por um programa aprovado em termos oficiais. Tem a data de 7 de Agosto de 1838 o primeiro programa de estudos académicos da Politécnica, submetido a alunos de "catorze annos de idade completos, com approvação em leitura, escripta, e Grammatica Portugueza, e nas quatro operações fundamentaes d'Arithmetica" (Programa, 1838: p. 6).

O lente proprietário da 11. a cadeira, Manuel Joaquim Pereira da Silva, reconduzido no cargo, uma vez que era ele o docente de Comércio em 1837 aquando da extinção da Academia Real da Marinha e Comércio da Cidade do Porto (GONÇALVES; MARQUES, 
2011a), assistiu (bem como os seus colegas de magistério) à passagem administrativa ('perdão de acto') dos seus cinco pupilos, "por carta de lei de 1838 em que foram dispensados dos actos todos os estudantes que, pela matrícula e frequência, estavam habilitados para fazêlos" (BASTO, 1937, p. 177).

Os estudos da cadeira de Comércio anunciam-se como segue no Quadro 5.

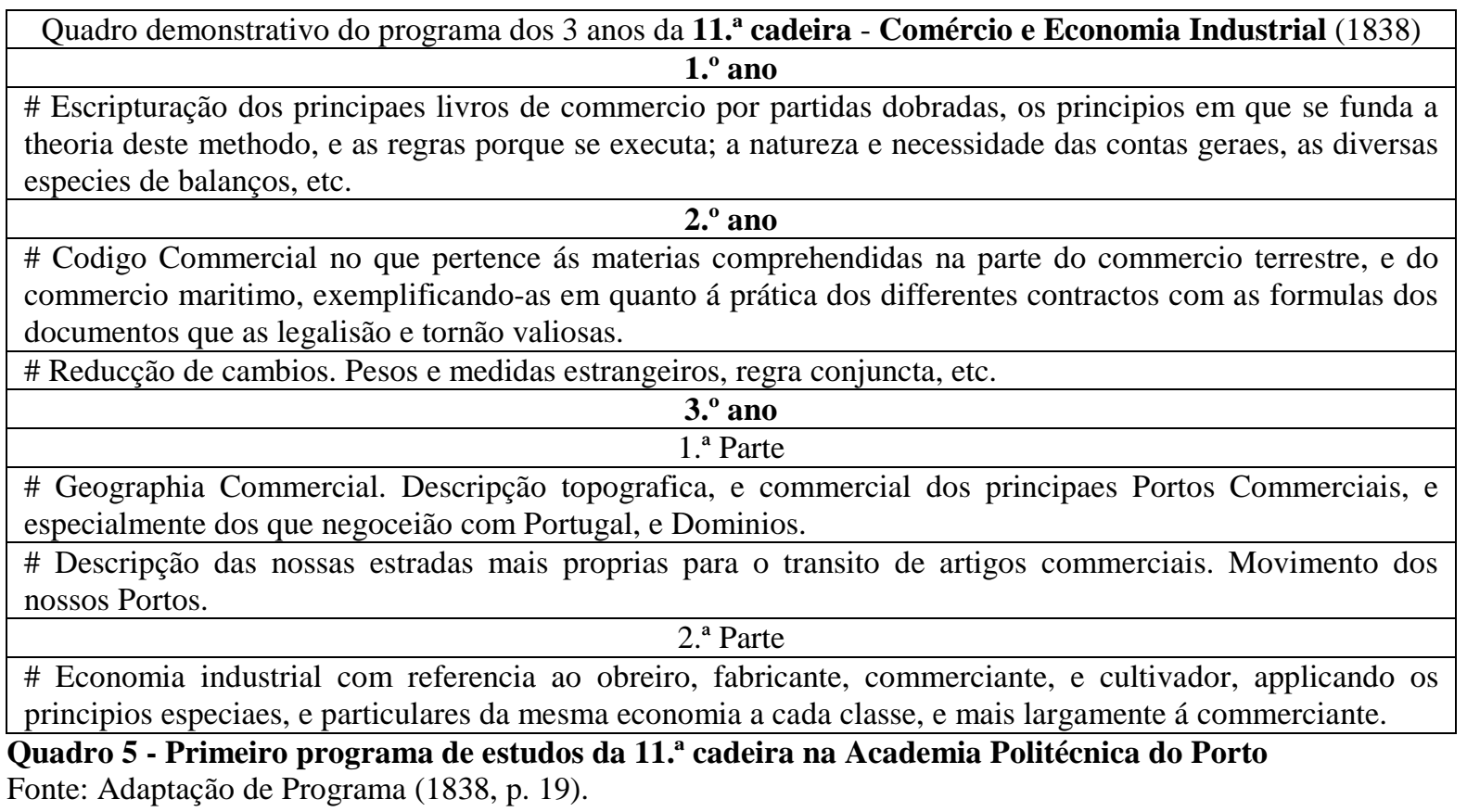

Do nosso ponto de vista, os conteúdos programáticos evidenciados no Quadro 5 merecem a interpretação crítica que segue.

Em 1838, o termo corrente para a nossa especialidade era o de 'Escrituração'. Nesta disciplina era usual começar-se por colocar em evidência as vantagens do método das partidas dobradas sobre o método das partidas singelas (ou simples). Os manuais da época normalmente dedicavam atenção a esta questão. Borges $(1839$, p. 356), por exemplo, alude à superioridade do método italiano ao explicar o funcionamento das partidas dobradas, dizendo, sucintamente, que "é menos sugeito a erro, porque é mais fácil errar escrevendo uma cousa uma so vez, do que duas". O programa de estudos de 1838, na parte final relativa aos obrigatórios 'Exercicios Praticos' a adestrar aos alunos da 11. a cadeira, confirma a leitura que aduzimos: "o lente exercitará os estudantes na arte de escripturar os livros por Partidas Dobradas á medida que for enunciando os seus preceitos, fazendo-lhes sentir a preferencia que este methodo merece sobre o das Partidas Singelas" (PROGRAMA, 1838, p. 30). Subsidiariamente, a preocupação do Conselho Académico em vincular os alunos, em termos oficiais, a 'Exercicios Praticos', também na forma de escrituração dos diversos livros auxiliares (caixa, letras a pagar, letras a receber, etc.), denota que, na Politécnica do Porto, "a theoria sem a pratica não passava de bella concepção; é preciso por tanto uni-las para lhes dar uma existencia proveitosa á sociedade" (PROGRAMA, 1838, p. 20).

Quanto às regras de execução da Contabilidade, forçoso será situarmo-nos em 1838, com o objectivo de, à luz do contexto de então, compreendermos que as regras de movimentação das contas repercutiam ainda a Summa de Pacioli, em parte. De um modo geral, as regras sobre as quais o método italiano se firmava eram empíricas, artificiais e incoerentes, facilitando o trabalho, por certo, mas não conseguindo apresentar uma fórmula geral que permitisse contabilizar todas as operações. Um caso concreto, ao explicar as partidas dobradas, Borges (1839) enumerava duas regras principais de movimentação de 
contas, complementadas com oito secundárias. Eram frequentes, no entanto, manuais com listas bem mais extensas, cada qual com as suas ficções. A máxima contista clássica "quem recebe deve e quem entrega tem a haver", evoluíra para "a conta que recebe deve à conta que entrega". Era com esta última regra que se explicava a Contabilidade e só com Jean Dumarchey (1874-1946) é que a situação veio a modificar-se quando matematicamente o autor formulou regras gerais de movimentação do débito e do crédito (AMORIM, 1947; ROSA, 1947; MARQUES; ALMEIDA, 2001).

As apreciações supra não configuram uma crítica negativa ao programa de estudos, mas servem tão-somente para nos capacitarmos que o ensino da Contabilidade na Academia Politécnica do Porto reproduzia o modelo em vigor na Europa contista de então.

Como é sabido, o $1 .^{\circ}$ Código Comercial Português, da autoria do eminente advogado especializado em questões comerciais José Ferreira Borges, serviu de lei vigente a partir de 1833 (até ao ano de 1888). Silva (1938, p. 49-50) refere que o trabalho marcou "um notável progresso numa matéria em que, até ali, tudo eram dúvidas, divergências e arbitrariedades". O professor Gonçalves da Silva afirmava, ainda, que o Código de Ferreira Borges foi considerado por muitos, no seu tempo, como o melhor do mundo (GONÇALVES DA SILVA, 1938). Por este motivo, estudá-lo com profundidade revela-nos, necessariamente, que o Conselho Académico da Politécnica entendia o Direito Comercial como uma das matérias fundamentais que um bom Contabilista deveria dominar.

Relativamente ao comércio português, o principal continuava a ser o marítimo. No Porto, a Alfândega era a segunda em termos de estatísticas de receita para a Fazenda (BORGES, 1839). Não é de admirar, portanto, que a Politécnica portuense dedicasse atenção a esta matéria na cadeira de Comércio.

Inovatório nos parece o estudo de parte da rede viária nacional. Neste particular, Pacheco (2001) informa que a partir do triunfo do Liberalismo, em 1834, Portugal vislumbrou condições e vontade política para definir objectivos e princípios orientadores da construção da rede viária. Assim, sob este pano de fundo, a Politécnica mostrou que estava atenta às discussões do país e claramente na vanguarda dos estabelecimentos de ensino de Comércio, porquanto um profissional de Contabilidade conhecedor das estradas nacionais veria facilitadas as operações comerciais da sua firma e, fundamentalmente, segundo cremos, veria diminuídas as despesas de transporte, as quais teriam a mesma influência directa sobre os preços que uma redução no custo da produção.

Por último, assinale-se o ineditismo da 2..$^{a}$ parte do $3 .^{\circ}$ ano - Economia Industrial disciplina a ministrar não só ao curso de Comércio, mas também ao $5 .^{\circ}$ ano do Curso de Direcção de Fábricas, mostrando a visão estratégica de que os profissionais da Contabilidade e Comércio formados na Politécnica poderiam também desempenhar funções de gestão nas fábricas.

\section{CONDICIONALISMOS DO NORMAL PROCESSO DE ESCOLARIZAÇÃO COMERCIAL}

Demos notícia anteriormente do parco número de discípulos do curso no primeiro ano da Politécnica; cinco, apenas. Como justificação para esta redução - o movimento discente passou de 229 para 120 no primeiro ano da Politécnica e para 112 no ano lectivo sequente (BASTO, 1937) - devemos ter presente que a frequência na Politécnica não era gratuita. A questão não é de somenos, na medida em que o Conselho Académico, no relatório final do ano lectivo 1838-1839, insistindo na necessidade de tomar providências a tal respeito, apurava que "o gravame das matrículas, num instituto que tem por fim o ensino das ciências industriais, ao qual concorrem necessáriamente classes menos abastadas, na verdade quási neutraliza os benéficos intuitos da sua criação" (BASTO, 1937, p. 215). 
Vem esta conclusão ainda mais robustecida, porquanto oferecia a Academia a possibilidade de frequência a alunos 'Ouvintes', isto é, estudantes que, não sendo 'Ordinários', podiam assistir às aulas, pagando um valor de propina inferior. Registe-se que não encontrámos elementos que nos permitissem averbar o montante de redução de propinas para os alunos 'Ouvintes'.

Como prova evidente de que o elevado valor das propinas afastava a demanda pelos estudos de Contabilidade, Basto (1937, p. 178) regista que ao $1 .^{\circ}$ ano de Comércio, aquele que facultava estudos de escrituração por partidas dobradas, "assistiam, em Dezembro de 1838, mais de trinta 'Ouvintes', além dos alunos matriculados ['Ordinários']". Se a esta circunstância aliarmos o facto de apenas três alunos matriculados se terem inscrito ordinariamente no ano lectivo 1838-1839, parece antever-se que, a haver dez vezes mais alunos 'extra-ordinarios', a razão do pouco movimento discente e da escassa procura pelo curso de Comércio pode relacionar-se com o alto custo das propinas que impossibilitava aos estudantes de classes mais desfavorecidas a frequência regular do curso.

No mesmo sentido podemos questionar quais os factores, para além das propinas elevadas, que terão contribuído para um número tão pouco expressivo de estudantes de Contabilidade nos primeiros anos de existência da Academia. Na expressão dos autores que temos vindo a seguir - Lopes (1915), Santos (1996) e, principalmente, Basto (1937) - este conjunto deve integrar essencialmente três ordens de razões.

Primeiro, o desfasamento de horários da cadeira de Comércio, após o início do ano lectivo 1838-1839 iniciado a 22 de Outubro. Ocupando o período lectivo das oito às nove e meia da manhã, três vezes por semana, a cadeira não poderia apresentar grande movimento, levando em linha de conta:

a rigidez de horário que os patrões impunham aos caixeiros e marçanos aquando da abertura das suas lojas e outros estabelecimentos, sendo de prever que da parte destes não houvesse qualquer facilidade perante um sistema educativo longe de criar a figura jurídica do trabalhador-estudante (PEREIRA, 2001, p. 284-285).

Segundo, a omissão no decreto reformador de 13 de Janeiro de 1837 de privilégios oferecidos aos diplomados que obtivessem carta de capacidade no curso, o que equivale a dizer que as vantagens conferidas aos diplomados não foram replicadas pelo decreto orgânico que fundou a Academia Politécnica do Porto, nomeadamente as proporcionadas pela Carta de Lei de 30 de Agosto de 1770 (garantias dos graduados pela Aula de Comércio de Lisboa) e pelo Alvará de 29 de Julho de 1803 (regalias dos graduados pela Aula de Comércio do Porto). Todavia, seguindo de perto Pereira (2001), o Código Comercial Português, de 1833, no seu art. 1063, estabelecia a garantia de que os escrivães dos tribunais do Comércio deviam ter feito, com aprovação, o Curso das Aulas de Comércio de Lisboa ou do Porto. Tratava-se, com rigor, de um tímido, mas real, privilégio oferecido aos praticantes das Aulas de Comércio.

Terceiro, a conjuntura política do final da primeira metade de Oitocentos, com "pelo menos cinco golpes de Estado com sucesso e duas guerras civis (1837 e 1846-1847) entre 1834 e 1851" (RAMOS, 2010, p. 491), não auxiliava o esforço daqueles que, no Porto, mas também em Lisboa, tentavam fazer recrudescer a frequência dos alunos nos cursos de Contabilidade e Comércio.

\section{DIGRESSÃO BREVE ATRAVÉS DO VETUSTO MUNDO DA POLITÉCNICA}

Até ao virar do século, podemos sumariar os aspectos mais relevantes do percurso da Politécnica na sequência cronológica de episódios.

Em 1838 - a Carta de Lei de 7 de Abril de 1838 prescrevia que para se ser Guarda- 
Livros não era necessária aprovação pela Aula de Comércio (quer de Lisboa, quer do Porto, na Politécnica).

Em 1844 - o Decreto de 20 de Setembro, referendado por Costa Cabral, Ministro do Reino de um governo presidido pelo General Duque da Terceira (1842-1846), devolve alguns privilégios aos formados que apresentassem carta de capacidade obtida na Politécnica do Porto, na Escola de Comércio de Lisboa (sucessora da Aula de Comércio, após 1844), ou no curso correspondente da antiga Aula de Comércio lisboeta.

Em 1844 - o citado Decreto de Costa Cabral reduz o valor da propina da Politécnica do Porto, a pagar em duas tranches no "principio de cada anno e igual quantia no fim d'elle" (RIBEIRO, 1876, p. 171).

Em 1854 - o deputado Oliveira Pimentel apresentou nas Cortes o seu famoso projecto de reforma da instrução pública, o qual, muito simplesmente, pretendia suprimir a Academia (NUNES, 1997). A indignação motivou uma reacção oficial, por escrito, assinada por todos os lentes da Politécnica que, uma vez dirigida aos deputados da nação, politicamente os terá sensibilizado a não conferir apoio a tal iniciativa.

Em 1857 - criação para os alunos do curso de Comércio de uma nova cadeira: 'Economia Política e Princípios de Direito Comercial e Administrativo', a 12. a cadeira, a funcionar a partir de 1858-1859.

De 1854 a 1878 - no curso de Comércio apenas seis comerciantes conseguiram direito a obter a carta de capacidade (SANTOS, 1996).

Em 1863 - Luiz Baptista Pinto de Andrade sucede a Manuel Joaquim Pereira da Silva como professor de Contabilidade e Comércio. Pereira da Silva exerceu o seu magistério durante vinte e cinco anos (1838-1863); Pinto de Andrade, apenas quatro (1863-1867).

Em 1867 - José Joaquim Rodrigues de Freitas (1840-1896) é nomeado lente proprietário da $11 .^{\text {a }}$ cadeira (Comércio e Economia Industrial). Rodrigues de Freitas veio a fazer carreira docente na Politécnica do Porto no ensino de Comércio e Economia (em 1864 havia sido nomeado lente substituto da 12. ${ }^{\mathrm{a}}$ cadeira - Economia Política e Princípios de Direito Comercial e Administrativo), mas formara-se na Academia numa área diversa Engenharia (Civil) de Pontes e Estradas, em 15 de Julho de 1862. Para um perfil mais completo sobre o professor e político Rodrigues de Freitas, siga-se Santos (1997) e Nunes (1997).

Em 1885 - Wenceslau de Lima, lente da Politécnica do Porto e deputado, vê aprovado um projecto de lei, por si proposto às Cortes, o qual estende o leque de cadeiras da Academia para dezoito. Por outro lado, neste ano de 1885, com a reforma de Wenceslau de Lima, Rodrigues de Freitas assume a regência da 17. cadeira (Comércio), passando o curso a bienal com o plano curricular conforme Quadro 6.

\begin{tabular}{|c|l|l|l|}
\hline \multicolumn{3}{|c|}{ Programa da 17..$^{\text {a }}$ cadeira - Comércio (curso de 2 anos) } & ano 1885 \\
\hline ANO & DIVISÃO & DISCIPLINAS & OBSERVAÇÕES \\
\hline $1 .^{\circ}$ & $1 .^{\text {a Parte }}$ & Cálculo Comercial. Escrituração em geral e especialmente dos bancos & 2 lições semanais \\
\hline & $2 .^{\text {a }}$ Parte & Contabilidade Industrial & lição semanal \\
\hline $2 .^{\circ}$ & $1 .^{\text {a }}$ Parte & Economia Comercial e Geografia Comercial & 3 lições semanais \\
\hline
\end{tabular}

Quadro 6 - A Contabilidade na Academia Politécnica do Porto: reorganização de 1885

Fonte: Basto (1937, p. 426).

Em 1886 - criação do Instituto Industrial e Comercial do Porto, com um curso de Comércio análogo.

Em 1897 - supressão do curso de Comércio devido à escassa frequência de alunos e à criação de um curso similar no Instituto Industrial e Comercial do Porto (SANTOS, 1997). 


\section{CONCLUSÕES}

A Academia Politécnica, nos anos que se seguiram à reforma de 1885 , e até ao seu ocaso, em 1911, sofreu uma notável transformação, o que se traduziu, como há muito se esperava, num acréscimo de matrículas. O pico atingiu-se no ano lectivo 1895-1896, com 347 alunos matriculados individualmente. Dois anos antes, inscreveram-se 343 estudantes. Estes foram os dois melhores anos da Politécnica, em termos de matrículas (SANTOS, 1996). No último período lectivo da sua actividade, 1909-1910, inscreveram-se 269 alunos.

Todavia, o curso de Comércio e a disciplina de Contabilidade não puderam acompanhar esse ritmo de crescimento, ora porque o curso estivesse pessimamente organizado (FREITAS, 1881b), nas palavras do lente proprietário de Comércio (Rodrigues de Freitas), ora porque talvez devesse ser nocturno (FREITAS, 1881b).

São também factores inibidores de maior projecção dos estudos de Contabilidade na Academia Politécnica do Porto, os seguintes: (1) a propina elevada; (2) a falta de instalações condignas (o edifício herdado da Academia Real da Marinha e Comércio só foi concluído em 1899); (3) o desfasamento entre horários do curso de Comércio e a disponibilidade dos estudantes; (4) a pouca vontade política em proteger os diplomados com garantias de emprego e em reformar o curso de Comércio; (5) a falta de visão estratégica dos responsáveis governamentais em apostarem de forma sustentável no ensino técnico mercantil; e (6) a concorrência de um curso similar no Instituto Industrial e Comercial do Porto, a partir de 1886.

Ainda que a média de alunos matriculados tivesse sido de oito na década de 40 do século XIX, de treze na década de 50, de quatro na de 60 e de apenas dois na de 70 (BASTO, 1937), a verdade é que o curso de Comércio mostrou sempre uma firme resiliência durante sessenta anos (1837-1897), não obstante a crueza decrescente dos números.

O programa de estudos académicos de Contabilidade professado na Politécnica, mormente o de 1838, tratou-se, a nosso ver, do mais completo e melhor estruturado programa que Portugal conhecera, desde logo porque se subdividia em três anos, sem os preparatórios obrigatoriamente exclusivos de um primeiro ano matemático, como na Aula de Comércio do Porto, em 1803 (GONÇALVES, 2011a), mas, sobretudo, porque os saberes conexos à Contabilidade, Direito Comercial, Geografia Económica e Economia Industrial, especialmente, imprimiam-lhe uma dimensão de polivalência e interdisciplinaridade, atributos ainda hoje solicitados à profissão contabilística.

Esta pesquisa abre portas a novas oportunidades de investigação, de que constituem exemplos estudos prosopográficos dos lentes de Comércio da Academia e trabalhos acerca das saídas profissionais dos diplomados de Comércio. Espera-se também que a exposição efectuada permita a abertura de novos trilhos de investigação no domínio da História da Contabilidade Portuguesa e Brasileira, nomeadamente em matérias relacionadas com Escolas de Comércio fundadas depois da aula pombalina (1759).

\section{REFERÊNCIAS}

AMORIM, J.L. Dumarchey e a sua obra. Revista de Contabilidade e Comércio, v. 57, p. 23-50, 1947.

ANDERSON-GOUGH, F. Education. In: EDWARDS, J.R.; WALKER, S. (eds.). Routledge Companion to Accounting History. London \& New York: Routledge Taylor \& Francis Group, 2009. pp. 297-316.

ANTONI, T. Las escuelas de ábaco en Pisa en el siglo XIV. Técnica Contable, v. 457, 1987. pp. 19-22.

ARQUERO MONTAÑO, J.L.; DONOSO ANES, J.A. Inicios de las enseñanzas oficiales de 
comercio en España: creación de la Escuela de Comercio de Cádiz (1799-1804) - selección de los primeros profesores, métodos de enseñanza y programas, con especial referencia a los de contabilidad. Congresso AECA, 11., 2000, Madrid, Espanha. Anais... Madrid, Espanha, 2000. pp. 1-19.

ARQUERO MONTAÑO, J.L.; DONOSO ANES, J.A. Inicios de las enseñanzas oficiales de comercio en España: creación de la Escuela de Comercio de Cádiz (1799-1804) - selección de los primeros profesores, métodos de enseñanza y programas, con especial referencia a los de contabilidad. Revista de Contabilidad, v. 8, n. 15, p. 183-214, 2005.

AZEVEDO, M.C. A Aula do Comércio, primeiro estabelecimento de ensino técnico profissional oficialmente criado no mundo. Lisboa: Edição da Escola Comercial Ferreira Borges, 1961.

AZEVEDO, R.A. O Porto na época moderna: da Academia Real da Marinha e Comércio do Porto à Academia Politécnica do Porto. Porto: Oficinas Gráficos Reunidos, 1982.

BASTO, A.M. Memória histórica da Academia Politécnica do Porto - precedida da "Memória sobre a Academia Real da Marinha e Comércio" pelo conselheiro Adriano de Abreu Cardoso Machado. Porto: Universidade do Porto, 1937.

BORGES, J.F. Dicionário Jurídico-Comercial. Lisboa: Tipografia da Sociedade Propagadora dos Conhecimentos Úteis, 1839.

CAIADO, A.P. The teaching of Accounting in Aula do Comércio (1759-1844). World Congress of Accounting Historians, 8., 2000, Madrid, Espanha. Anais... Madrid, Espanha, 2000. pp. 1-9.

CAMPOS, J.F. Apontamentos relativos à instrução pública. Lisboa: Tipografia da Academia Real das Ciências, 1859.

CARDOSO, J.L. Uma 'notícia esquecida': o ensino da Economia na Aula do Comércio. Estudos de Economia, v. 5, n. 1, p. 87-112, 1984.

CARMONA, S. Accounting history research and its diffusion in an international context. Accounting History, v. 9, n. 3, p. 7-23, 2004. http://dx.doi.org/10.1177/1032373204009 00302

CARMONA, S.; ZAN, L. Mapping variety in the history of accounting and management practices. European Accounting Review, v. 11, n. 2, p. 291-304, 2002. http://dx.doi.org/10.1080/09638180220125526

CARNEGIE, G.D.; NAPIER, C.J. Critical and interpretative histories: insights into accounting's present and future through its past. Accounting, Auditing \& Accountability Journal, v. 9, n. 3, p. 7-39, 1996. http://dx.doi.org/10.1108/09513579610121956

CARQUEJA, H.O. Do saber da profissão às doutrinas da academia. Revista de Contabilidade e Comércio, Separata Anexa 234-235, p. 1-144, 2002.

CARVALHO, R. História do ensino em Portugal: desde a fundação da nacionalidade até ao fim do regime de Salazar-Caetano. 3. ed. Lisboa: Fundação Calouste Gulbenkian, 2001.

CARVALHO, R. História do ensino em Portugal: desde a fundação da nacionalidade até ao fim do regime de Salazar-Caetano. 4. ed. Lisboa: Fundação Calouste Gulbenkian, 2008.

COSTA, C.B. O Ensino da Contabilidade em Portugal: a necessidade de uma licenciatura em Contabilidade. Revista de Contabilidade e Comércio, v. 176, p. 389-404, 1980.

COSTA, C.B. Breves notas sobre a Aula de Comércio. Revista de Contabilidade e Finanças 
(Portugal), v. 96, p. 4-5, 2009.

ESTEVENS, M. Classe média: o universo provável dos discentes da Aula de Comércio? Revista de Contabilidade e Finanças (Portugal), v. 99, p. 4-8, 2009.

FELISMINO, A. No duplo centenário da Aula do Comércio. Lisboa: [s.n.], 1960.

FERnÁndeZ AGUADO, J. Historia de la Escuela de Comercio de Madrid y su influencia en la formación gerencial española. Madrid: Asociación Española Contabilidad y Administración de Empresas, 1997a.

FERNÁNDEZ AGUADO, J. Los comienzos oficiales de la Escuela de Comercio de Madrid: 1850-1887. Cuadernos de Estudios Empresariales, v. 7, p. 117-138, 1997 b.

FERNÁNDEZ AGUADO, J. Los estudios de Contabilidad en la Escuela de Comercio de Madrid (1828-1922). Congresso AECA, 9., Salamanca, Espanha. Anais... Salamanca, Espanha, 1997c. Tomo I.

FERREIRA, L.; KEDSLIE, M.; FREITAS, M.V. The history of accounting in Portugal, with special reference to the Aula do Commercio. European Accounting Association Annual Congress, 18., 1995, Birmingham, Reino Unido. Anais... Birmingham, Reino Unido, 1995.

FERREIRA, R.F. Contabilidade e terminologias em mudança. Revista de Contabilidade e Finanças (Portugal), v. 100, p. 23, 2010.

FLEISCHMAN, R.K.; MILLS, P.A.; TYSON, T.N. A theoretical primer for evaluating and conducting historical research in accounting. Accounting History, v. 1, n. 1, p. 55-75, 1996. http://dx.doi.org/10.1177/103237329600100104

FREITAS, J.J.R. Instrução Industrial e Comercial I. O Comércio do Porto. In: ALVES, J.F. (recolha e introd.). José Joaquim Rodrigues de Freitas: novas páginas avulsas. Porto: Fundação Eng. ${ }^{\circ}$ António de Almeida, 1881a. pp. 125-127.

FREITAS, J.J.R. Instrução Industrial e Comercial VI. O Comércio do Porto. In: ALVES, J.F. (recolha e introd.). José Joaquim Rodrigues de Freitas: novas páginas avulsas. Porto: Fundação Eng. ${ }^{\circ}$ António de Almeida, 1881b. pp. 139-143.

GARCÍA-FUENTES, M. Las Escuelas de Comercio en el siglo XIX: la escuela de la Coruña. Gestión Empresarial, v. 3, p. 32-39, 1984.

GOMES, D.; RODRIGUES, L.L. Investigação em história da Contabilidade. In: MAJOR, M.J.; VIEIRA, R. (eds.). Contabilidade e controlo de gestão: teoria, metodologia e prática. Lisboa: Escolar Editora, 2009. pp. 211-239.

GONÇALVES, J.C.S. A Aula do Comércio. Lisboa: [s.n.], 1960.

GONÇALVES, M. Bosquejo de uma sucinta história da Contabilidade em Portugal até à fundação da primeira escola de Comércio e Contabilidade (1759). Revista Universo Contábil, v. 6, n. 4, p. 89-103, 2010a. http://dx.doi.org/10.4270/ruc.2010433

GONÇALVES, M. Escola de Comércio e memória histórica dos primeiros professores e estudantes de Contabilidade (Parte I). Revista da Ordem dos Técnicos Oficiais de Contas, v. 127, p. 56-64, 2010 b.

GONÇALVES, M. Escola de Comércio e memória histórica dos primeiros professores e estudantes de Contabilidade (Parte II). Revista da Ordem dos Técnicos Oficiais de Contas, v. 128, p. 47-54, 2010c.

GONÇALVES, M. Aula de Comércio do Porto (1803): sua criação e confronto crítico com a correlativa Aula lisboeta. Contabilidade e Gestão 10 - Revista Científica da Ordem dos 
Técnicos Oficiais de Contas (Portuguese Journal of Accounting and Management), p. 115163, 2011a.

GONÇALVES, M. Escola de Comércio de Lisboa, 1844-1869: contributo para a história do ensino da Contabilidade em Portugal. Revista de Contabilidade e Finanças (Portugal), v. 106, p. 12-17, 2011 b.

GONÇALVES, M. E depois da Aula de Comércio, 1844? Digressão através do ensino da Contabilidade na Lisboa Oitocentista. Jornal de Contabilidade, v. 420, p. 87-100, 2012.

GONÇALVES, M.; MARQUES, M.C.C. Uma 'História não Contada': o ensino da Contabilidade na Aula de Comércio do Porto. Jornal de Contabilidade, v. 413, p. 246-248, 2011 a.

GONÇALVES, M.; MARQUES, M.C.C. On the interrelations between accounting education and the state: the teaching of accounting at the Oporto School of Commerce. In: Before and After Luca Pacioli - a cura di Esteban Hernández Esteve e Matteo Martelli, pp. 641-652. Incontro Internazionale Before and After Luca Pacioli, 2., 2011, Sansepolcro-Perugia-Firenze, Itália. Anais... Centro Studi 'Mario Pancrazi' - Associazone per la valorizzazione della cultura delle matematiche; Spanish Association for Accounting and Business Management Accounting History Association; Società Italiana di Storia della Ragioneria, 2011b.

HOPWOOD, A.G. The tale of a committee that never reported: disagreements on intertwining accounting with the social. Accounting, Organizations and Society, v. 10, n. 3, p. 361-377, 1985. http://dx.doi.org/10.1016/0361-3682(85)90025-X

LIRA, M.M.C. A Importância da Aula de Comércio na história da Contabilidade Portuguesa. Revista Universo Contábil, v. 7, n. 2, p. 97-113, 2011. http://dx.doi.org/ 10.4270/ruc. 2011215

LOPES, E. Genealogia duma escola: origens e tradições da Academia Politécnica (17621911). Coimbra: Imprensa da Universidade, 1915.

LOPES, F.C. História da Contabilidade - A Aula do Comércio: primeira escola de gestores em Portugal. Jornal do Técnico de Contas e da Empresa, v. 320, p. 127-128, 1992.

MACHADO, A.J.C. A importância das reformas pombalinas do ensino na evolução da Contabilidade. Revista de Contabilidade e Finanças (Portugal), v. 98, p. 4-8, 2009.

MAFFRE, P. Les origines de l'enseignement commercial supérieur en France au XIXe siècle. Tese de doutoramento em História. Paris: University Paris I, 1983.

MAFFRE, P. La comptabilité dans les écoles supériéures de commerce au XIX ${ }^{\mathrm{e}}$ siecle. Revue Historique, v. 276, n. 1, p. 133-156, 1986.

MARQUES, M.C.C.; ALMEIDA, J.J.M. A influência da teoria positiva da Contabilidade de Dumarchey na estruturação do pensamento contabilístico português. Revista de Contabilidade e Comércio, v. 229, p. 189-211, 2001.

MARTINS, E.; SILVA, A.F.; RICARDINO, A. Escola Politécnica: possivelmente o primeiro curso formal de contabilidade do estado de São Paulo. Revista Contabilidade \& Finanças (FEA/USP), v. 17, n. 42, p.113-122, 2006. http://dx.doi.org/10.1590/S151970772006000300010

MARTINS, R.M.E. A Aula do Comércio. Revista de Contabilidade e Comércio, v. 19, p. 262-265, 1937.

MARTINS, R.M.E. A Aula do Comércio: 1759. Lisboa: [s.n.], 1960. 
NAPIER, C.J. Accounts of change: 30 years of historical accounting research. Accounting, Organizations and Society, v. 31, n. 4/5, p. 445-507, 2006. http://dx.doi.org/ 10.1016/j.aos.2005.12.004

NUNES, M.F. Rodrigues de Freitas: da Academia Politécnica do Porto ao publicismo oitocentista. Notas dispersas. In: Rodrigues de Freitas: a obra e os contextos. Colóquio Faculdade de Letras, Centro Leonardo Coimbra. Anais... Porto: Universidade do Porto, 1997.

PACHECO, E. Alteração das acessibilidades e dinâmicas territoriais na região norte: expectativas, intervenções e resultantes. Tese de doutoramento em Geografia. Porto: Faculdade de Letras da Universidade do Porto, 2001.

PELEIAS, I.R.; SILVA, G.P.; SEGRETI, J.B.; CHIROTTO, A.R. Evolução do ensino da contabilidade no Brasil: uma análise histórica. Revista Contabilidade \& Finanças (FEA/USP), v. 18, n. especial, p.19-32, 2007. http://dx.doi.org/10.1590/S151970772007000300003

PEREIRA, J.M. O caixeiro e a instrução comercial no Porto Oitocentista: percursos, práticas e contextos profissionais. Dissertação de Mestrado em História Contemporânea. Faculdade de Letras da Universidade do Porto, Porto, 2001.

PEREIRA, J.M. O ensino comercial público do Porto oitocentista. Revista de Contabilidade e Comércio, v. 237, p. 95-146, 2006.

PEREIRA, J.M. O arranque do ensino comercial no Porto oitocentista - pretextos e contextos. Revista de Contabilidade e Finanças (Portugal), v. 97, p. 4-13, 2009.

PORTELA, A.F. A evolução histórica do ensino das ciências económicas em Portugal. Análise Social, v. 6, n. 22-23-24, p. 787-836, 1968.

PORTUGAL. Carta de Lei de 30 de Agosto de 1770. Privilégios conferidos aos diplomados pela Aula de Comércio de Lisboa, 1770.

PORTUGAL. Alvará de 29 de Julho de 1803. Estatutos das Aulas da Academia Real da Marinha e do Comércio da Cidade do Porto, 1803.

PORTUGAL. Decreto de 13 de Janeiro de 1837. Lei Geral da Instrução Pública (conhecida pela reforma de Passos Manuel), 1837.

PORTUGAL. Carta de Lei de 7 de Abril de 1838. Prescreve, entre outros assuntos, que para se ser Guarda-Livros não é necessária aprovação pelas Aulas de Comércio, 1838.

PORTUGAL. Decreto de 20 de Setembro de 1844. Reforma da Instrução Pública em Portugal (conhecida pela reforma de Costa Cabral), 1844.

PREVITS, G.J.; MERINO, B.D. A history of Accounting in America: an historical interpretation of the cultural significance of Accounting. New York: John Wiley \& Sons, 1979.

PROGRAMA dos Estudos da Academia Politécnica do Porto no Ano Lectivo de 1838 para 1839. Porto: Imprensa Constitucional, 1838.

RAMOS, R. A Revolução Liberal (1834-1851). In: RAMOS, R.; SOUSA, B.V.; MONTEIRO, N.G. (coord.). História de Portugal. 4. ed. Lisboa: A Esfera dos Livros, 2010. pp. 491-519.

RAUPP, F.M.; BEUREN, I.M. Metodologia da pesquisa aplicável às Ciências Sociais. In: Beuren, I.M. (org.). Como elaborar trabalhos monográficos em Contabilidade: teoria e prática. 3. ed. São Paulo: Atlas, 2006. pp. 76-97. 
RIBEIRO, J.S. História dos estabelecimentos científicos, literários e artísticos de Portugal nos sucessivos reinados da monarquia. Lisboa: Tipografia da Academia Real das Ciências, 1876. Tomo VI.

RODRIGUES, L.L.; CRAIG, R. English mercantilist influences on the foundation of the Portuguese School of Commerce. Atlantic Economic Journal, v. 32, n. 4, p. 329-345, 2004. http://dx.doi.org/10.1007/BF02304238

RODRIGUES, L.L.; CRAIG, R. Influências mercantilistas inglesas na criação da Aula do Comércio em 1759. Revista da Câmara dos Técnicos Oficiais de Contas, v. 62, p. 22-33, 2005.

RODRIGUES, L.L.; CRAIG, R. Teachers as servants of state ideology: Sousa and Sales, Portuguese School of Commerce, 1759-1784. Critical Perspectives on Accounting, v. 20, n. 3, p. 379-398, 2009. http://dx.doi.org/10.1016/j.cpa.2007.11.001

RODRIGUES, L.L.; CRAIG, R.; GOMES, D. State intervention in commercial education: the case of the Portuguese School of Commerce, 1759. Accounting History, v. 12, n. 1, p. 55-85, 2007. http://dx.doi.org/10.1177/1032373207072808

RODRIGUES, L.L.; CRAIG, R.; GOMES, D. A intervenção do estado no ensino comercial: o caso da Aula do Comércio, 1759 (I). Revista da Ordem dos Técnicos Oficiais de Contas, v. 118, p. 39-48, 2010a.

RODRIGUES, L.L.; CRAIG, R.; GOMES, D. A intervenção do estado no ensino comercial: o caso da Aula do Comércio, 1759 (II). Revista da Ordem dos Técnicos Oficiais de Contas, v. 119 , p. 39-44, 2010 b.

RODRIGUES, L.L.; GOMES, D. Evolução da profissão dos TOC em Portugal: do Marquês de Pombal até aos nossos dias. Jornal de Contabilidade, v. 302, p. 131-141, 2002.

RODRIGUES, L.L.; GOMES, D.; CRAIG, R. Aula do Comércio: primeiro estabelecimento de ensino técnico profissional oficialmente criado no mundo? Revista da Câmara dos Técnicos Oficiais de Contas, v. 34, p. 46-54, 2003.

RODRIGUES, L.L.; GOMES, D.; CRAIG, R. Corporativismo, liberalismo e a profissão contabilística em Portugal desde 1755. Revista da Câmara dos Técnicos Oficiais de Contas, v. 46, p. 24-39, 2004a.

RODRIGUES, L.L.; GOMES, D.; CRAIG, R. Portuguese School of Commerce, 1759-1844: a reflection of the 'Enlightenment'. Accounting History, v. 9, n. 3, p. 53-71, 2004b. http://dx.doi.org/10.1177/103237320400900304

RODRIGUES, L.L.; RICARDINO, A.; MARTINS, S.T.A. 'Corporate governance regulations': a new term for an ancient concern? The case of Grão-Pará and Maranhão General Trading Company in Portugal (1754). Accounting History, v. 14, n. 4, p. 405-435, 2009. http://dx.doi.org/10.1177/1032373209342475

RODRIGUES, L.L.; SCHMIDT, P.; SANTOS, J.L.; FONSECA, P.C.D. A research note on accounting in Brazil in the context of political, economic and social transformations, 18601964. In: Accounting History International Conference, 6., 2010, Wellington, New Zealand. Anais... Wellington, New Zealand, 2010.

RODRIGUES, L.L.; SCHMIDT, P.; SANTOS, J.L.; FONSECA, P.C.D. A research note on accounting in Brazil in the context of political, economic and social transformations, 18601964". Accounting History, v. 16, n. 1, p. 111-123, 2011. http://dx.doi.org/10.1177/1032373210373799 
ROSA, G. Jean Dumarchey na escala dos valores morais. Revista de Contabilidade e Comércio, v. 57, p. 63-75, 1947.

SANTANA, F.G. A Aula do Comércio: uma escola burguesa em Lisboa. Ler História, v. 4, p. 19-30, 1985.

SANTOS, C. Universidade do Porto: raízes e memória da instituição. Porto: Universidade do Porto, 1996.

SANTOS, C. A Academia Politécnica do Porto no tempo de Rodrigues de Freitas. In: Rodrigues de Freitas: a obra e os contextos. Colóquio Faculdade de Letras, Centro Leonardo Coimbra. Anais... Porto: Universidade do Porto, 1997.

SILVA, A. Contra a corrente: "Contabilistas melhorados". Revista de Contabilidade e Finanças (Portugal), v. 97, p. 24, 2009.

SILVA, F.V.G. A regulamentação legal da escrituração mercantil: esboço crítico. Lisboa: Tipografia da Empresa Nacional de Publicidade, 1938.

STEWART, R.E. Pluralizing our past: Foucault in Accounting History. Accounting, Auditing and Accountability Journal, v. 5, n. 2, p. 57-73, 1992. http://dx.doi.org/10.1108/09513579210011862

VIEIRA, R.; MAJOR, M.J; ROBALO, R. Investigação qualitativa em Contabilidade. In: MAJOR, M.J.; VIEIRA, R. (eds.). Contabilidade e controlo de gestão: teoria, metodologia e prática. Lisboa: Escolar Editora, 2009. pp. 131-163. 